Theatre Buildings,

Corporation Street,

St. Helens,

WA10 1DZ

Merseyside.

To the Editor

18th October, 1977

\title{
MOUTHGUARDS FOR RUGBY FOOTBALL PLAYERS
}

Dear Sir,

Further to the articles in the June issue of the British Journal of Sports Medicine, I have been designing, constructing and fitting mouthguards for the majority of rugby league football players and rugby union football players in the Merseyside and Lancashire area for the past 17 years and I can confirm that I have never seen mouth injuries when an individually-made protector has been constructed and fitted by a dental surgeon.

Since my article in the British Dental Journal (October 7, 1969), "Mouth Protection for the Rugby Football Player", when I described a mouth protector with an outer shell of acrylic resin with a soft lining and lower biting surface, I have been using a new type of mouthguard for rugby players. For the past 6 years I have used a white vinyl plastic type of material, constructed over an accurate model of the wearer's teeth and extended only to the back of the upper second premolar teeth. It is comfortable to wear, has excellent retention, does not cause nausea or dryness of the mouth and has no adverse effects on the oral mucosa, breathing or speech. I would be only too pleased to give any of my colleagues further information if they so require it.

On numerous occasions over the past 17 years whilst watching rugby in this country, every winter week-end and in Australia, New Zealand and France with the St. Helens Rugby League Team, I have attended to many players in serious trouble and near to death through blockage of the air-way. Blockage of the air-way occurred on the field after a bad facial injury, accompanied by concussion, swallowing of the loose protector and tongue because the player was wearing either a badly fitting stock-type of protector, or a badly-fitting self-made mouth form of protector. I consider that the British Dental Association should press the D.H.S.S. to promote legislation to ban the sale of these types of mouthguards in sport shops for rugby football players. In the interest of safety when playing rugby football British Dental Association and D.H.S.S. policy should be that a mouth protector should not be sold, made or fitted unless under strict supervision of a dental surgeon, and under no circumstances by a sports player taking his own impression and having his own mouthguard constructed.

\section{Yours faithfully,}

John H. Clegg, L.D.S., J.P.

Honorary Dental Surgeon,

St. Helens Rugby League F.C.

\section{REFERENCES}

Blonstein, J. L., Cutler, R. and Mason, Marion. Mouth and jaw protection in contact sports. 1977. Brit.J.Sports Med. 11 75-79.

Clegg, J. H. 1969. Mouth protection for the Rugby football player. Brit.Dental Journ. Vol. 127, No. 7 pp. $341-343$, October 7, 1969.

Davies, R. M., Bradley, D., Hale, R. W., Laird, W. R. E. and Thomas, P. D. 1977. The prevalence of dental injuries in rugby players and their attitude to mouthguards. Brit.J.Sports Med. 11 72-74. 